\title{
Photocurable temperature activated humidity hybrid sensing materials for multifunctional coatings
}

Cristian Mendes-Felipe ${ }^{1,2, *}$, Manuel Salado ${ }^{1}$, Liliana C. Fernandes ${ }^{1,3}$, Daniela M. Correia $^{3,4}$, Leire Ruiz-Rubio ${ }^{1,2}$, Mohammad Tariq ${ }^{5}$, José M.S.S. Esperança ${ }^{5}$, J. L. VilasVilela $^{1,2}$, S. Lanceros-Mendez ${ }^{1,6}$

${ }^{1}$ BCMaterials, Basque Center for Materials, Applications and Nanostructures, UPV/EHU Science Park, 48940 Leioa, Spain.

${ }^{2}$ Macromolecular Chemistry Group (LABQUIMAC), Department of Physical Chemistry, Faculty of Science and Technology, University of the Basque Country (UPV/EHU), Barrio Sarriena s/n, E-48940 Leioa, Spain.

${ }^{3}$ Center of Physics, University of Minho, Campus de Gualtar, de 4710-057 Braga, Portugal.

${ }^{4}$ Center of Chemistry, Universidade de Trás-os-Montes e alto Douro, 5001-801 Vila Real, Portugal.

${ }^{5}$ LAQV, REQUIMTE, Departamento de Química, Faculdade de Ciências e Tecnologia, Universidade Nova de Lisboa, 2829-516 Caparica, Portugal.

${ }^{6}$ Ikerbasque, Basque Foundation for Science, 48009, Bilbao, Spain. 


\begin{abstract}
Photocurable thermochromic and humidity responsive materials based on polyurethane acrylated (PUA) and bis(1-butyl-3-methylimidazolium) tetrachloronickelate ([Bmim $]_{2}\left[\mathrm{NiCl}_{4}\right]$ ) ionic liquid (IL) have been prepared with varying IL content up to 40 wt.\% within the polymer matrix. The influence of IL content on the photopolymerization process, morphology, Young modulus and electrical conductivity of the materials was evaluated. All materials present a total polymer conversion of at least $88 \%$. The presence of the IL influences the morphology of PUA, being observed a porous network structure upon IL incorporation into the PUA matrix. All samples show a $\mathrm{T}_{\mathrm{g}}$ around room temperature, which is independent of the IL content and a Young modulus that decreases with the IL content. All composites exhibit humidity dependent thermochromism from colourless to blue. Further, the influence of the relative humidity in the colour change was accessed for the sample containing $20 \mathrm{wt} . \%$ [Bmim $]_{2}\left[\mathrm{NiCl}_{4}\right]$, being observed that the colour variation is thermally activated and humidity governed, being $55 \%$ the minimum value of the relative humidity for colour change to occur.
\end{abstract}

\title{
Keywords
}

UV curing; Polyurethane acrylate; Ionic liquids; $[\mathrm{Bmim}]_{2} \mathrm{NiCl}_{4}$; Humidity sensor; Thermochromic materials 


\section{Introduction}

VP is mainly composed by UV or visible light curable processes in which the light activates the photopolymerization process $[1,2]$. The use of UV curable materials is increasing rapidly because the fast curing method, from seconds to minutes, at room temperature, and without using volatile organic compounds, as it occurs in solvent based processes. In addition, this technique reduces the overall energy consumption, based on space and energy efficiency, and allows the fabrication of high-resolution patterns [3]. However, a small range of materials can be used, with limited functionality, and supporting materials are often required during fabrication [4].

The Internet of Things (IoT) has become a key element to truly implement the requirements of the Industry 4.0 [5,6]. The IoT concept emerges to define the interconnectivity of heterogeneous technologies related to the daily needs and activities, and includes cyber-physical devices embedded with software, electronics, sensors and actuators, among others [7]. In this context, sensors together with $2 \mathrm{D}$ and 3D printing [8] are becoming increasingly demanded and significant over the past years [9]. In this respect, different photocurable materials for sensor applications have been obtained, in some cases using AM techniques, including biosensor [10], piezoresistive [11], tactile [12], acoustic [13], optical [14], temperature [15] and gas detection [16] sensors.

Most of the above mentioned sensors rely on multifunctional materials that are generally obtained from nanocomposites. This makes nanocomposites an essential tool for the development of sensing materials and applications, mainly based in the synergetic effect of both nanomaterial and matrix [17], the former providing functionality and the second structure and process ability. Thus, several efforts have been devoted to the synthesis of polymer nanocomposites [18-20], including UV curable one [21]. Nevertheless, performance, cost, environmental and safety concerns, as well as the processing of materials at industrial scale continues to be a problem for nanocomposites [22]. In this sense, hybrid materials based on ionic liquids (ILs) dispersed within a polymer matrix allow the development of advanced materials with improved properties than conventional nanocomposites based on inorganic or organic nanoparticles. This increases the interest in developing those novel materials for different application areas, particularly for sensing [23]. 
ILs are composed entirely of organic cations and organic or inorganic anions [24]. Due to their tuneable intrinsic characteristics, including high ionic conductivity, mechanical, electrical, electromechanical and thermal stability, as well as, negligible vapour pressure, ILs have been attracting a great interest for an increasing number of applications. They have also been implemented as green solvents for polymeric, organic and inorganic materials presenting an alternative to volatile organic solvents and electrolytes [25].

These materials can also show the ability of responding to external stimuli, such as $\mathrm{pH}$ or temperature, by alteration of their properties thus adapting to environmental conditions [26]. The tunability of ILs is possible due to the large variety of possible options of cations and anions, promoting their implementations as smart and sensing materials, including electrochromic and thermochromic materials, among others $[25,26]$.

Different polymers were used as a matrix to develop ILs based hybrid polymer composites, such as poly(vinylidene fluoride) (PVDF) and its copolymers, poly(methyl methacrylate) (PMMA), poly(N-isopropylacrylamide) (PNIPAM), poly(urethane) (PU), polyethylene (PE) and poly(lactic acid) (PLA), among others [23]. Different and very diverse applications have been demonstrated for these nanocomposites, from sensors and actuators or batteries and fuel cells to air and water remediation or biomedical applications [23]. Furthermore, ILs/polymer hybrid materials were obtained based on UV curable materials such as PNIPAM with phosphonium-based ILs for ionogels fabrication [27] or methacrylic oligomer with imide salt type IL to be applied as electrolytes in lithium-based batteries [28]. Further, UV cured IL/polymer hybrid materials were prepared by $3 \mathrm{D}$ printing, using photosensitive commercial photoresist (IP-L 780 or SU-8) combined with dicyanamide salt and printed by two-photon nanolithography to obtain good optical transparent and down to $200 \mathrm{~nm}$ resolution 3D structures [29]; or phosphonium polymerized ionic liquids structures for emerging electro-active membrane technologies printed by microstereolithography [30].

UV-curable polymers are particularly suited for smart coating applications, namely as coatings for corrosion protection, inks and adhesives [31]. However, besides the large potential of these materials, few studies are dedicated to the development of smart coatings curing by UV light, being polyurethane (PU) coatings the most commonly 
employed. In this sense, PU coatings produced by UV curing presents many advantages, being related with their low environmental impact, energy and time saving processing and an efficient polymerization. Smart coatings based on polyurethane (PU) and fluorated octavinyl polyhedral oligomeric silsesquioxane (F-OV-POSS) developed by UV curing revealed a self-cleaning ability and durability, based on their superhydrophobicity. These interesting results demonstrate their strong potential to be used in the still to develop area of smart and multifunctional coatings [31].

With the capability of reversibly changing colour with varying temperature, thermochromic materials, in particular IL/polymer materials have been gained special attention in the field of sensors, such as level sensors [32]. This thermochromic behaviour is present in halide complexes, different transition-metal complexes, including nickel or copper, due to the interaction of the transition metal with a donor solvent by the energy alteration of the $d-d$ transitions and consequent configuration changes [33]. Systems based on thermochromic materials are being applied in areas such as energy [34], flexible electronics [35] or sensors [36], among others. In this sense, thermochromic materials and, particularly, ILs based ones, are the focus of increasing attention $[23,32]$. Besides the high interest in thermochromic materials, few studies reported on the IL/polymer based thermochromism. Printable level sensors based on the IL bis(1-butyl-3-methylimidazolium) tetrachloronickelate $\left([\mathrm{Bmim}]_{2}\left[\mathrm{NiCl}_{4}\right]\right)$ and the polymer PVDF able to change colour from transparent to a dark blue, have been reported [32].

The potentiality of the ILs as humidity sensors have also been explored [37]. ILs/PVDF composites [37], photopolymerizable polymers with carbon nanotubes [38] or polyelectrolytes based on 2-(dimethylamino)ethyl methacrylate quaternized with nbutyl bromide [39] or based on trimethylolpropane triacrylate (TMPTA) and different ammonium salts [40] have been developed.

Besides the great advantages of the ILs for the development of multifunctional materials and the advantages of UV curable polymers for additive manufacturing and protective and functional coatings [41], no studies concerning thermochromic IL-based UV curable hybrid materials able to change the colour with the temperature and to detect relative humidity variations (humidity sensor) have been reported. 
Thus, UV curable ILs/polymer thermochromic and humidity responsive material are presented in this work, based on polyurethane acrylate (PUA) and bis(1-butyl-3methylimidazolium) tetrachloronickelate $\left([\mathrm{Bmim}]_{2}\left[\mathrm{NiCl}_{4}\right]\right)$ able to be implemented as multifunctional materials or coatings with thermochromic and for humidity sensing capability. 


\section{Experimental}

\subsection{Materials}

SPOT-E ${ }^{\mathrm{TM}}$ from SPOT-A Materials ${ }^{\circledR}$ commercial photoresin has been selected as UV curable matrix. This clear-yellowish material is based on polyurethane acrylate (PUA) polymer. The IL, 1-buthyl-3-methylimidazolium tetracholonickelate $\left([\mathrm{Bmim}]_{2} \mathrm{NiCl}_{4}\right)$, with a purity of $99 \%$ was synthetized as previously reported [42,43]. 2-propanol of 99.5 $\%$ purity from Alfa Aesar ${ }^{\circledR}$ was used as a sample cleaner.

\subsection{Sample preparation}

Samples with varying $[\mathrm{Bmim}]_{2} \mathrm{NiCl}_{4}$ content $(0,5,10,20$ and $40 \mathrm{wt} . \%)$ were prepared by mixing the IL with the corresponding volume of the photoresin. To ensure a good mixture of the resin and the IL, the samples were dispersed under ultrasonication (ATU® ATM series Model ATM3L) for $1 \mathrm{~h}$ at $30^{\circ} \mathrm{C}$ and magnetically stirred for $2 \mathrm{~h}$ at $45^{\circ} \mathrm{C}$. After the completely homogeneous photoresin-IL mixture, flexible films were obtained by doctor blade spreading the mixture on a glass substrate. The samples were cured at room temperature for 90 seconds (UVACUBE 400, Honle UV America, Inc., mercury lamp $1000 \mathrm{~W} / \mathrm{m}^{2}$ of irradiance). Finally, the films were peeled off from the glass substrates, washed in a 2-propanol bath during 5 minutes, dried, and finally, stored in the dark at room temperature for the subsequent characterization. IL/PUA hybrid materials with a thickness around $150 \mu \mathrm{m}$, determined by an electronic digital caliper of Powerfix ${ }^{\circledR}$, were obtained. Figure 1 shows a scheme of the preparation process for PUA and IL/PUA films. 


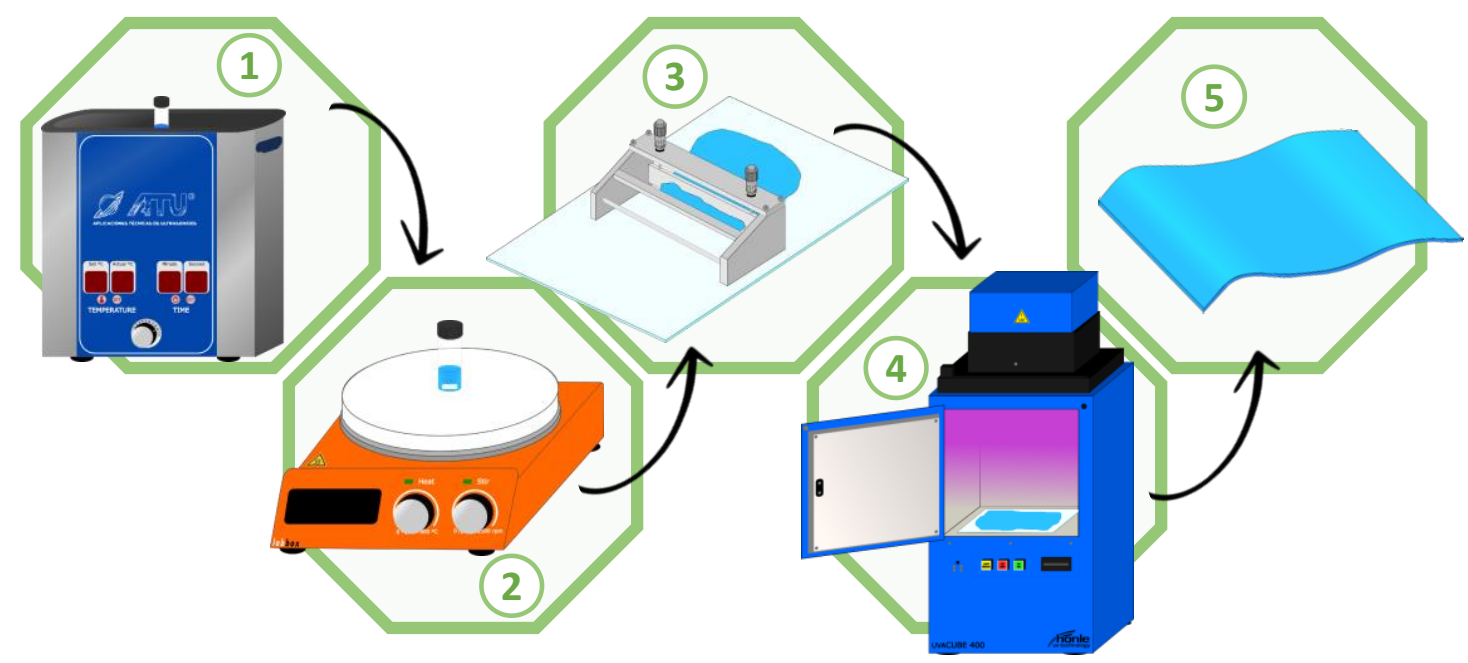

Figure 1. Representation of the development of the PUA and IL/PUA composite films $(5,10,20$ and 40 wt.\%): 1 - ultrasonication, 2 - magnetic stirring at $45^{\circ} \mathrm{C}, 3$ - film processing by Doctor Blade, 4-UV cure, 5 - flexible films.

\subsection{Characterization of the samples}

The effect of the introduction of the IL within the polymer in the UV curing process was quantified by photo-differential scanning calorimetry (photo-DSC) using a DSC 2920 Modulated DSC equipment coupled to a differential photocalorimetry from TA Instruments ${ }^{\circledR}$. All samples were irradiated with UV light at room temperature for 5 minutes while the heat flow was measured. The results were normalized by the weight of the photoresin included in each sample, which depends on the ionic liquid content within them.

The $\mathrm{C}=\mathrm{C}$ double bonds conversion $(\alpha)$ was obtained according to Equation 1 [44]:

$$
\alpha=\frac{\Delta H_{t}}{\Delta H_{0}^{\text {theor }}}
$$

where $\Delta H_{t}$ is the enthalpy at time $\mathrm{t}$ (calculated from the integration of the area under the peak of the DSC curves), and $\Delta H_{0}^{\text {theor }}$ is the theoretical enthalpy for the full conversion; both in J/g. Due to fact that a commercial photoresin was used, the enthalpy of the pure resin after complete UV cure was considered as the theoretical enthalpy for totally conversion $[11,45]$.

The photopolymerization rate $\left(\mathrm{R}_{\mathrm{p}}\right)$ was obtained applying Equation 2: 


$$
R_{p}=\frac{d \alpha}{d t}=\frac{d H / d t}{\Delta H_{0}^{\text {theor }}}
$$

Thus, the maximum photopolymerization rate $\left(R_{p}^{\max }\right)$ and the time to reach $R_{p}^{\max }$, named $\mathrm{t}^{\mathrm{max}}$, were obtained.

Scanning Electron Microscopy (SEM) was employed to evaluate the morphology variations of the samples. Samples were cold fractured under liquid nitrogen bath and cross-section images were obtained with a Hitachi S-4800 microscope (accelerating voltage of $10 \mathrm{kV}$, magnification of $500 \times$ ).

IL - polyurethane acrylate possible chemical interactions were studied by Fourier transformed infrared spectroscopy in the total attenuated reflection mode (FTIR-ATR) using a Nexus FTIR Nicolet spectrophotometer. The FTIR-ATR analysis was performed from 4000 to $400 \mathrm{~cm}^{-1}$ with a resolution of $4 \mathrm{~cm}^{-1}$ and 64 scans.

Differential scanning calorimetry (DSC) was measured under nitrogen atmosphere in two successive scans from -50 to $250{ }^{\circ} \mathrm{C}$ at $20^{\circ} \mathrm{C} / \mathrm{min}$ in the first scan and from -50 to $150^{\circ} \mathrm{C}$ at $20^{\circ} \mathrm{C} / \mathrm{min}$ in the second scan (DSC $822 \mathrm{e}$, Mettler Toledo). The cooling process between the first and second scans, from $250{ }^{\circ} \mathrm{C}$ to $-50{ }^{\circ} \mathrm{C}$ was made with a cooling rate of $20^{\circ} \mathrm{C} / \mathrm{min}$. The glass transition temperature was obtained as the extrapolated endset of the baseline shift in both heating processes. In addition, the water absorption capability of the samples was also evaluated in the first scan.

Contact angle measurements were employed to characterize the hydrophobic/hydrophilic behaviour of the prepared films as a function of the amount of IL in the samples. The Ossila Contact Angle Goniometer was used to measure the contact angle of each sample over time (3 experiments per sample). Drops of Mili-Q water were deposited on each sample $(10 \mu \mathrm{L} / \mathrm{drop})$ and the evolution of the contact angle over time was measured.

The mechanical properties of the samples were evaluated by tensile tests. Mechanical tests in the tensile mode were carried in a universal testing machine (Shimadzu model AG-IS) at room temperature using a load cell of $50 \mathrm{~N}$. Rectangular shaped (30 x 10 $\mathrm{mm}$ ) samples were analyzed at a test velocity of $10 \mathrm{~mm} / \mathrm{min}$. Secant modulus (E), obtained by calculating the slope of the linear region, and strain at break $\left(\varepsilon_{\mathrm{b}}\right)$ were determined for pure PUA and IL/PUA films. 
The electrical properties of the films were evaluated at room temperature by currentvoltage (I-V) measurements (Keithley 6430 picoammeter/voltage source) in samples prepared in the form of a parallel plate condenser with deposited circular gold electrodes of $5 \mathrm{~mm}$ diameter (Polaron Coater SC502). The volumetric electrical conductivity was obtained by the slope of the characteristic I-V curves and the electrical conductivity $(\sigma)$ was calculated considering the geometrical factors of the samples according to Equation 3 [11]:

$$
\sigma=\frac{L}{R \cdot A}
$$

where $\mathrm{R}$ is the electrical resistance, $\mathrm{L}$ the thickness of the samples and $\mathrm{A}$ is the area of the electrodes.

The thermochromic response was investigated by ultraviolet-visible (UV-Vis) spectroscopy as a function of temperature. UV-Vis spectra were recorded with an Agilent Cary 60 UV/vis spectrophotometer with an external temperature controller. The spectra were obtained in the range of $300-800 \mathrm{~nm}$, with a resolution of $1 \mathrm{~nm}$, from 30 to $70{ }^{\circ} \mathrm{C}$ (temperature range in which sample colour changes) every $5{ }^{\circ} \mathrm{C}$ after 2 min stabilization before each measurement. Further, the effect of temperature and relative humidity $(\mathrm{RH})$ variation on the colour of the films was measured within a climate chamber Challenge 250E from ACS Company by recording photographs while RH and temperature were varied as indicated in Table 1. This analysis was carried out for the IL/PUA sample ( $2.5 \times 2.5 \mathrm{~cm}$ square) with $20 \mathrm{wt}$.\% IL content. In order to obtain the blue (dehydrated) initial state, the sample was kept at $70{ }^{\circ} \mathrm{C}$ for 5 minutes, while for the colourless (hydrated) state, the sample was kept under ambient conditions during 24 hours.

Table 1. Experimental details for thermochromic and relative humidity $(R H)$ variation assays.

\begin{tabular}{|c|c|c|c|c|c|}
\hline Experiment & Initial state & $\begin{array}{c}\text { Constant } \\
\text { parameter and } \\
\text { value }\end{array}$ & $\begin{array}{c}\text { Variable parameter } \\
\text { and interval }\end{array}$ & $\begin{array}{r}\text { Studied } \\
\text { intervals }\end{array}$ & $\begin{array}{l}\text { Time of } \\
\text { interval }\end{array}$ \\
\hline 1 & $\begin{array}{c}\text { Blue } \\
\text { (dehydrated) }\end{array}$ & $\begin{array}{c}\text { Temperature at } \\
25^{\circ} \mathrm{C}\end{array}$ & $\begin{array}{c}\text { Relative humidity } \\
15-85 \%\end{array}$ & $10 \%$ & \multirow{3}{*}{$\begin{array}{c}20 \text { minutes } \\
\text { at constant } \\
\text { value and } 15 \\
\text { minutes } \\
\text { increasing to }\end{array}$} \\
\hline 2 & $\begin{array}{c}\text { Blue } \\
\text { (dehydrated) }\end{array}$ & $\begin{array}{c}\text { Temperature at } \\
45^{\circ} \mathrm{C}\end{array}$ & $\begin{array}{c}\text { Relative humidity } \\
15-85 \%\end{array}$ & $10 \%$ & \\
\hline 3 & Blue & Temperature at & Relative humidity & $10 \%$ & \\
\hline
\end{tabular}




\begin{tabular}{|c|c|c|c|c|c|}
\hline & (dehydrated) & $10^{\circ} \mathrm{C}$ & $20-85 \%$ & \multirow{2}{*}{ the next step } \\
\cline { 1 - 5 } & $\begin{array}{c}\text { Colourless } \\
\text { (hydrated) }\end{array}$ & $\begin{array}{c}\text { Relative humidity } \\
\text { at } 60 \%\end{array}$ & $\begin{array}{c}\text { Temperature } \\
25-75{ }^{\circ} \mathrm{C}\end{array}$ & $10^{\circ} \mathrm{C}$ & \\
\cline { 1 - 4 } 5 & $\begin{array}{c}\text { Colourless } \\
\text { (hydrated) }\end{array}$ & $\begin{array}{c}\text { Relative humidity } \\
\text { at } 40 \%\end{array}$ & $\begin{array}{c}\text { Temperature } 25-75 \\
{ }^{\circ} \mathrm{C}\end{array}$ & $10^{\circ} \mathrm{C}$ & \\
\hline
\end{tabular}




\section{Results and discussion}

\subsection{UV curing process}

UV curing process for the samples is depicted in Figure 2. The photopolymerization conversion $(\alpha)$ as a function of time is shown in Figure $2 \mathrm{a}$ and the photopolymerization rate $\left(R_{p}\right)$ in Figure $2 b$. Table 2 presents the main values that characterize the UV curing process, $\alpha, \mathrm{R}_{p}^{\max }$ and $\mathrm{t}^{\max }$, of the different samples, as a function of IL content.


Figure 2. Curing conversion ( $\alpha$ ) as a function of time of the pristine photoresin and the IL/PUA samples $(a)$, and photopolymerization rate $\left(R_{p}\right)(b)$.

Table 2. UV curing process characteristic parameters of the pristine resin and the IL/PUA samples for the different IL contents.

\begin{tabular}{|c|c|c|c|}
\hline Sample & $\boldsymbol{\alpha ( \% )}$ & $\boldsymbol{R}_{\boldsymbol{p}}^{\max }\left(\mathbf{s}^{\mathbf{- 1}}\right)$ & $\mathbf{t}^{\mathbf{m a x}}(\mathbf{s})$ \\
\hline 0 wt.\% & 100 & 3.4 & $8.0 \pm 0.1$ \\
\hline 5 wt.\% & 99 & 3.4 & $8.0 \pm 0.2$ \\
\hline 10 wt.\% & 95 & 3.3 & $7.4 \pm 0.1$ \\
\hline 20 wt.\% & 89 & 3.2 & $7.0 \pm 0.3$ \\
\hline 40 wt.\% & 88 & 2.9 & $6.2 \pm 0.4$ \\
\hline
\end{tabular}

Figure $2 \mathrm{a}$ shows that a decrease on the conversion degree occurs with increasing IL content. Neat photoresin shows a $100 \%$ conversion after approximately 4 minutes that becomes $95 \%$ for the $10 \mathrm{wt} . \%$ IL content sample. Similar trend is further observed for the $20 \mathrm{wt} . \%$ and $40 \mathrm{wt} . \%$ IL content samples, the total conversion decreasing to around $88 \%$ for the 40 wt. $\%$ IL content sample after 4 minutes. In addition, photopolymerization rate is also slightly affected by the incorporation of [Bmim $]_{2}\left[\mathrm{NiCl}_{4}\right]$, changing from $3.4 \mathrm{~s}^{-1}$ for neat PUA to $2.9 \mathrm{~s}^{-1}$ for $40 \mathrm{wt}$ \% IL/PUA 
sample. In relation to the $\mathrm{t}^{\text {max }}$, a slight decrease is observed with increasing IL content, varying between $8.0 \mathrm{~s}$ for the $0 \mathrm{wt}$.\% IL/PUA sample to $6.2 \mathrm{~s}$ for the sample that contains the highest amount of IL.

The UV light absorption by the photoinitiator has significant influence in the conversion of the $\mathrm{C}=\mathrm{C}$ double bonds and, therefore, in the UV curing process [46]. The functionality and chemical structure of the employed oligomer influences in the reactivity of the photocurable ink and as consequence in the final degree of conversion [1]. Further, the viscosity of the liquid curable ink/resin also plays a relevant role on the photopolymerization and is affected by the addition of additives [45]. Further, the fillers could absorb UV light, competing with the photoinitiator and, as a consequence, influencing the photopolymerization reaction and the characteristic photopolymerization parameters [11].

In the present case, UV absorption by $\left[\mathrm{Bmim}_{2}\left[\mathrm{NiCl}_{4}\right]\right.$ competes with absorption of light by the photoinitiator $[42,47]$, reducing photoinitiator efficiency and, thus, lower amount of initiating radicals are obtained. As a consequence, the final conversion and the rate at which the polymerization occurs are reduced when IL is added to the PUA resin. Despite the ability of UV light absorption by the ionic liquid, according to its chemistry, it does not generate any species further interfering with the curing process.

Furthermore, increasing viscosity influences the photopolymerization by decreasing the rate and increasing the time to obtain the maximum curing degree [44]. Hence, two factors have to be taken into account: a) when the photopolymerization is taking place, the viscosity increases and b) the presence of IL also increases the viscosity of the photocurable material [27]. Thus, different viscosities could be obtained for two materials with the same degree of cure but different amount of IL content, being observed a decrease in the $\mathrm{R}_{\mathrm{p}}$ and $\mathrm{t}^{\mathrm{max}}$ with increasing $[\mathrm{Bmim}]_{2}\left[\mathrm{NiCl}_{4}\right]$ content.

\subsection{Morphological and contact angle characterization}

Figure 3 shows the cross-sectional SEM images of neat PUA and IL/PUA samples in order to evaluate morphology variations due to the $[\mathrm{Bmim}]_{2}\left[\mathrm{NiCl}_{4}\right]$ inclusion within the polymer. 

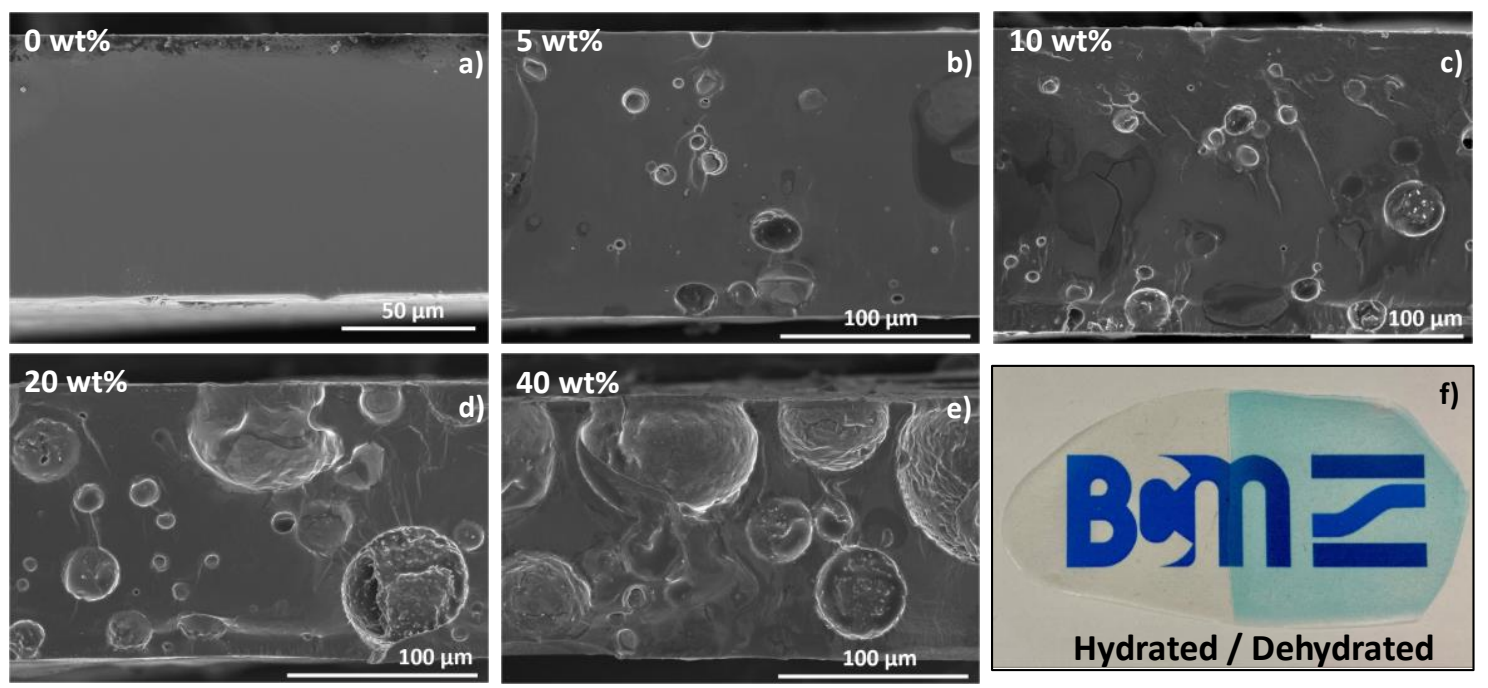

Figure 3. Representative SEM images of the PUA (a) and IL/PUA hybrid samples comprising different IL contents (b-e) at magnification of 300x. Thermochromism resulting from the dehydration process of IL/PUA with $10 \mathrm{wt} . \%$ IL content (f).

The filler induced morphological variations have significant influence over mechanical and electrical properties of the prepared samples [11,45], which depends on IL type and content [27]. Figure 3 shows that the presence of $[\mathrm{Bmim}]_{2}\left[\mathrm{NiCl}_{4}\right]$ modifies the PUA polymer morphology: whereas pristine PUA (Figure 3a) shows a smooth and flat structure, without any visible crack, pores or patters, the incorporation of the IL leads to spherical or porous like structures within the sample. This trend increases with increasing IL content within the PUA matrix and the pore distribution is homogeneous throughout the films. When IL content increases, the spherical (bubble type) structures appear in a greater extent and the pores seem to be larger [48].

The obtained SEM results are in agreement with elated studies with $[\mathrm{Bmim}]_{2}\left[\mathrm{NiCl}_{4}\right]$ within different polymer matrix $[32,37]$. Further, as the IL $[\mathrm{Bmim}]_{2}\left[\mathrm{NiCl}_{4}\right]$ is known by its thermochromic properties upon a hydration and dehydration process, an important property for the development of multifunctional materials for smart coatings and/or sensor applications, the thermochromism upon a hydration process was evaluated. Figure $3 \mathrm{f}$ shows the thermochromism occurring as a result of a hydration/dehydration process for the sample with $10 \mathrm{wt}$.\% IL content, as demonstrated by a colour change from colourless/whitish to light blue, respectively. This effect will be quantitatively analysed in this work. 
The surface wettability of the PUA and PUA/[Bmim $]_{2}\left[\mathrm{NiCl}_{4}\right]$ was evaluated by contact angle measurements (Figure 4). Attending to the contact angle values, the hydrophobic/hydrophilic behaviour of each sample can be evaluated.
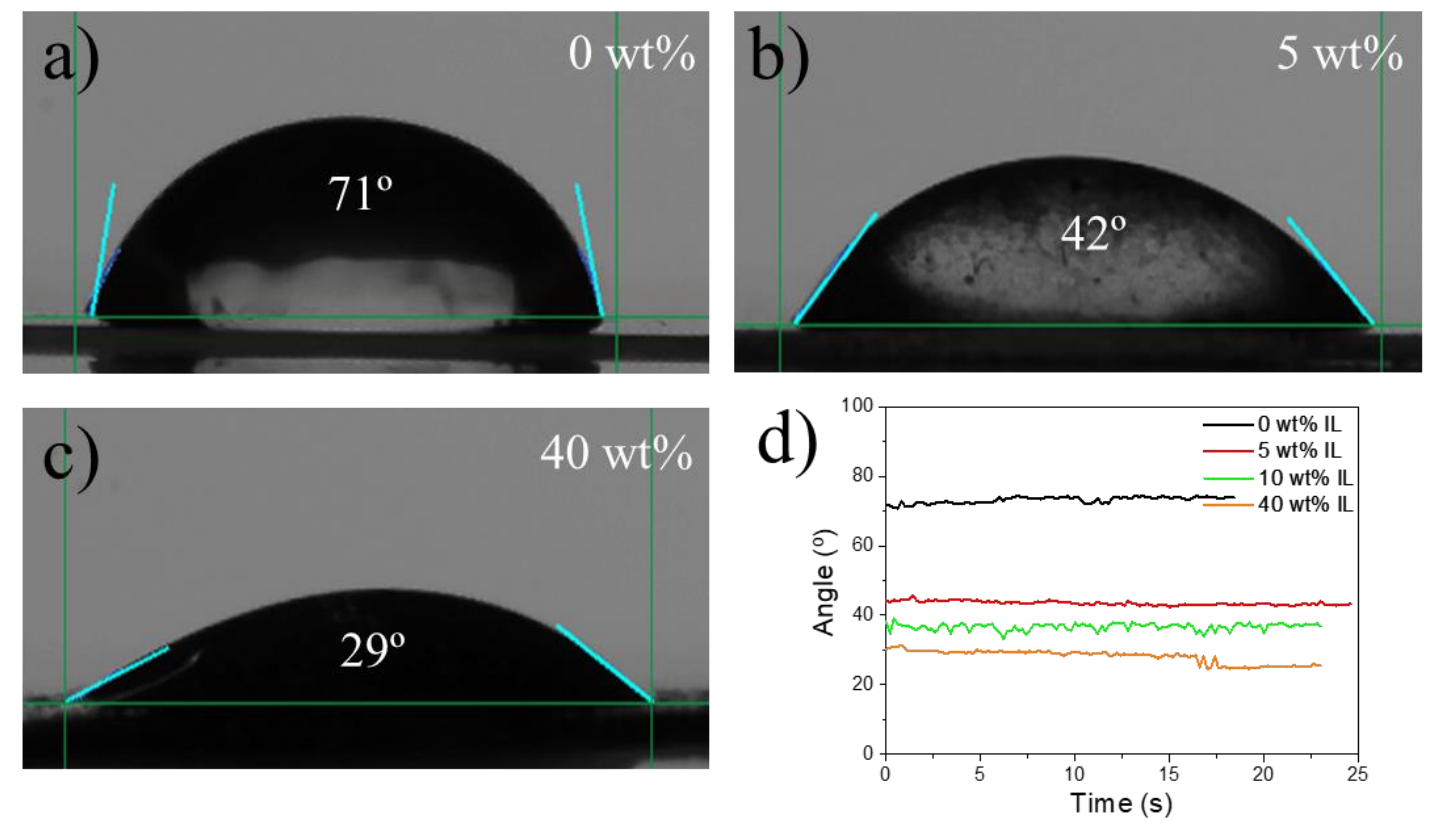

Figure 4. Representative images of the water surface contact angle for neat PUA film (a) and IL/PUA samples containing $5 \mathrm{wt. \%}(\mathrm{b}), 10 \mathrm{wt} . \%(\mathrm{c}), 20 \mathrm{wt} . \%(\mathrm{~d})$ and $40 \mathrm{wt} . \%(\mathrm{e})$. Evolution of the contact angle values as a function of time for the mentioned samples $(f)$.

Figure 4 shows that the contact angle for neat PUA films present a value of $71^{\circ}$ and that when the IL is added to the polymer matrix, the contact angle value decreases to $42^{\circ}$ for the $5 \mathrm{wt} . \%$ IL/PUA sample and to a minimum value of $29^{\circ}$ for the $40 \mathrm{wt}$.\% IL content sample. The improvement of the surface wettability of the samples with increasing $[\mathrm{Bmim}]_{2}\left[\mathrm{NiCl}_{4}\right]$ content shows that the inclusion of the IL into the polymer matrix improves the water absorption capability, increasing the absorbed water per unit mass in the IL/PUA samples [49]. The results are in agreement with the larger porosity of the samples with increasing IL content presented in Figure 3, as higher porosity allows a larger contact between film and water drop and increased water absorption [48].

\subsection{Thermal and chemical characterization}

The thermal properties of pristine and IL/PUA samples were evaluated by the DSC thermograms shown in Figure 5. Only a change (a step) in the base line is observed for neat PUA in the first and second scans, corresponding to the glass transition 
temperature $\left(\mathrm{T}_{\mathrm{g}}\right)$. The glass transition temperatures of the samples are indicated in Table 3.

Table 3. Glass transition temperature for first $\left(T_{g_{1}}\right)$ and second $\left(T_{g_{2}}\right)$ scans, strain at break $\left(\varepsilon_{b}\right)$ and elastic modulus (E) for PUA and IL/PUA films.

\begin{tabular}{|c|c|c|c|c|}
\hline Sample & $\mathbf{T}_{\mathbf{g} 1}\left({ }^{\mathbf{0}} \mathbf{C}\right)$ & $\mathbf{T}_{\mathbf{g} 2}\left({ }^{\mathbf{}} \mathbf{C}\right)$ & $\boldsymbol{\varepsilon}_{\mathbf{b}}(\boldsymbol{\%})$ & $\mathbf{E}(\mathbf{M P a})$ \\
\hline 0 wt.\% & 20.2 & 41.2 & $45.8 \pm 3.2$ & $4.04 \pm 0.35$ \\
\hline 5 wt.\% & 24.1 & 52.8 & $54.3 \pm 4.4$ & $4.87 \pm 0.37$ \\
\hline 10 wt.\% & 23.5 & 53.3 & $29.1 \pm 2.1$ & $4.20 \pm 0.13$ \\
\hline 20 wt.\% & 23.7 & 50.9 & $27.0 \pm 2.5$ & $4.27 \pm 0.31$ \\
\hline 40 wt.\% & 23.6 & 56.7 & $32.9 \pm 5.3$ & $3.45 \pm 0.02$ \\
\hline
\end{tabular}

a)

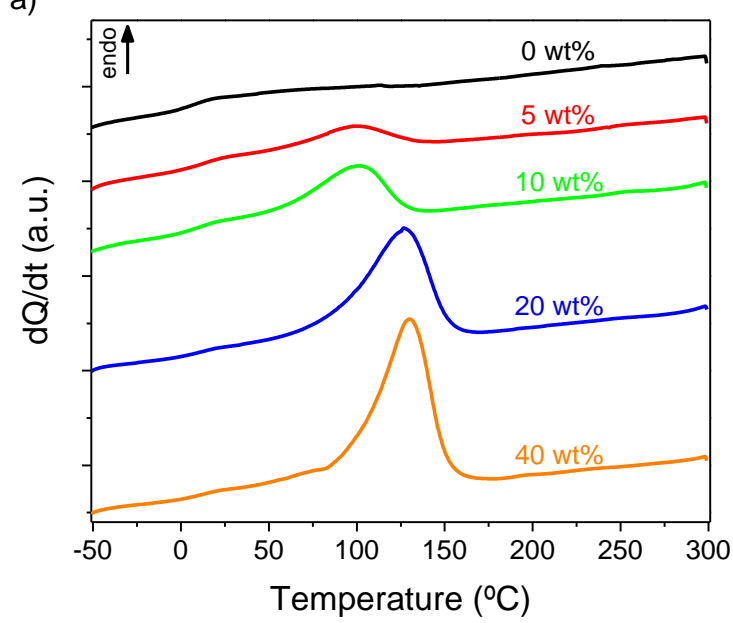

b)

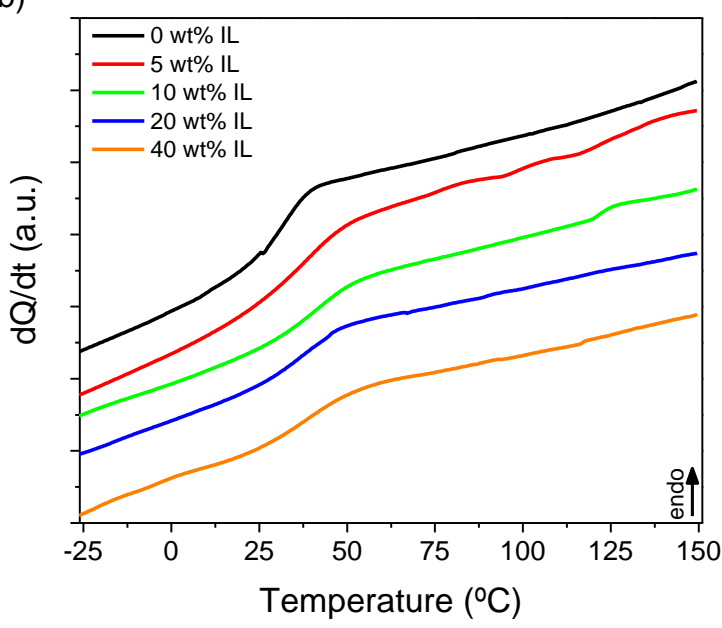

Figure 4. DSC thermograms of neat PUA and IL/PUA samples for the first (a) and second (b) scans.

For neat PUA the glass transition is located around room temperature $\left(\mathrm{T}_{\mathrm{g}}=20^{\circ} \mathrm{C}\right)$. With the incorporation of the IL $[\mathrm{Bmim}]_{2}\left[\mathrm{NiCl}_{4}\right]$ an endothermic peak is observed between 60 and $150^{\circ} \mathrm{C}$ that increases with IL content. This endothermic peak is related to water desorption and can appears at different temperature ranges depending on the $\mathrm{H}_{2} \mathrm{O}$ molecular interactions [50], being indicative in the present case of a reversible water desorption on $\mathrm{Ni}$ (II) compounds in which $\mathrm{H}_{2} \mathrm{O}$ molecules are coordinated to the metal [32,51]. The increase of the endothermic peak with increasing IL content is in agreement with contact angle results, where a higher wettability is observed for samples with higher IL content. Further, higher values at which the endothermic peak appears can be ascribed to the high heating rate used during the DSC scans. 
Figure 5a also shows that $\mathrm{T}_{\mathrm{g} 1}$ for neat PUA and IL/PUA samples (Table 3) slightly increases from 20 to $\sim 24{ }^{\circ} \mathrm{C}$ when $[\mathrm{Bmim}]_{2}\left[\mathrm{NiCl}_{4}\right]$ is added. This small change on the $\mathrm{T}_{\mathrm{g}}$ value can be associated to experimental errors (selection of the temperature or measurement uncertainties). In addition, this slightly increase can be also associated to a possible interaction between the ionic liquid and the polymer that hinders the polymer chains, reducing the free volume and therefore increasing the $\mathrm{T}_{\mathrm{g}}$. In any case, it can be concluded that no relevant differences are observed for the different samples.

After the heating process up to $300{ }^{\circ} \mathrm{C}$ and the subsequent cooling to $-50{ }^{\circ} \mathrm{C}$ the peak corresponding to the water absorption does not appear (Figure 5b), indicating that the hydration process does not occur. Related to PUA, $\mathrm{T}_{\mathrm{g}}$ increases compared with the first scan from $20{ }^{\circ} \mathrm{C}\left(\mathrm{T}_{\mathrm{g} 1}\right)$ to $41{ }^{\circ} \mathrm{C}\left(\mathrm{T}_{\mathrm{g} 2}\right)$, increasing further for samples with IL content up to $40 \mathrm{wt} . \%$, being $53{ }^{\circ} \mathrm{C}$ for $5 \mathrm{wt} . \%$ IL content sample and $56{ }^{\circ} \mathrm{C}$ for the one with 40 wt.\% IL. The increase of the $\mathrm{T}_{\mathrm{g} 1}$ of PUA with the IL incorporation indicates that the IL actually interacts with the polymer, reducing its mobility [52]. Thus, after the heating process and water evaporation (second scan), the increase of $\mathrm{T}_{\mathrm{g}}$ indicative of the polymer mobility reduction that can be ascribed to a IL and PUA interactions when dehydration has occurred [52]. Furthermore, a possible heat-activated post-curing process could occur, increasing $\mathrm{T}_{\mathrm{g}}$ of the samples from the first to the second scan. This process could be appreciated in the DSC thermogram of the first scan as an exothermic peak, but probably is not observed due to the high values of the endothermic peaks.

The IL- polymer physico-chemical interactions as well as the conformational variations of the IL/PUA samples after the hydration and dehydration processes were evaluated by FTIR-ATR. Figure 6 shows both the room temperature, $25{ }^{\circ} \mathrm{C}$, (hydrated) and $80{ }^{\circ} \mathrm{C}$ (dehydrated) FTIR spectra. 
a)

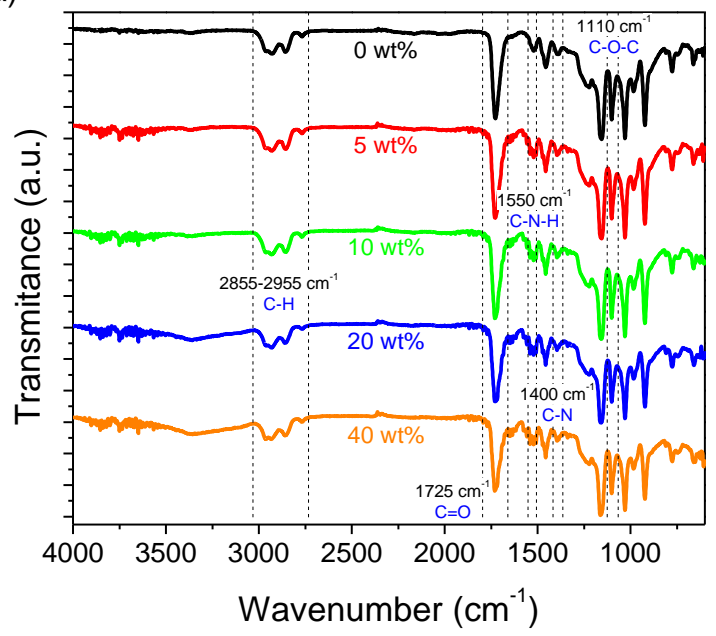

b)

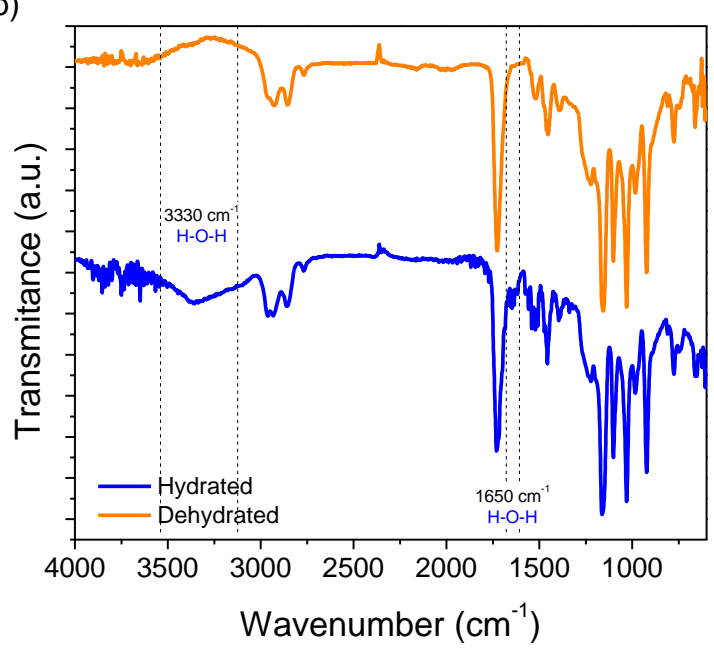

Figure 6. FTIR spectra of neat PUA and IL/PUA samples containing different IL contents (a) and FTIR spectra at room temperature (hydrated) and at $80^{\circ} \mathrm{C}$ (dehydrated) of $20 \mathrm{wt} . \%$ IL/PUA sample (b)

Figure 6a allows to identify the characteristic absorption bands of neat PUA. The absorption band at $1550 \mathrm{~cm}^{-1}$ is related to the stretching vibrations of $\mathrm{C}-\mathrm{N}$ and $\mathrm{N}-\mathrm{H}$ bonds of the urethane group. C-N and C-O-C absorption bands appear at $1400 \mathrm{~cm}^{-1}$ and $1110 \mathrm{~cm}^{-1}$, respectively. The $\mathrm{C}=\mathrm{O}$ stretching vibrations are observed at $1725 \mathrm{~cm}^{-1}$ and the $\mathrm{CH}_{2}$ and $\mathrm{CH}_{3}$ vibrations are observed between $2855 \mathrm{~cm}^{-1}$ and $2955 \mathrm{~cm}^{-1}$ [45]. No chemical changes are identified in the PUA FTIR-ATR spectra upon the IL incorporation within the polymer matrix. Additionally, it is also to notice that the characteristic IL imidazolium $\mathrm{CH}_{2}, \mathrm{CH}_{3}$ and $\mathrm{C}-\mathrm{N}$ absorption bands of the cation $[\mathrm{Bmim}]^{+}$are overlapping with the polymer absorption bands [32,37]. Apart from that, no band displacement or new absorption bands are observed upon the addition of IL, showing that no relevant intermolecular interactions occur between the IL and PUA polymer [45].

Comparing samples before (hydrated) and after (dehydrated) the heating process, it is to notice the presence of two absorption bands at 1650 and $3330 \mathrm{~cm}^{-1}$ in the hydrated samples, which correspond to water molecules stretching and bending modes [32]. These results indicate that the change in colour from light blue to colourless (Figure 3f) can be attributed to the presence or absence of water molecules within the coordination structure of the IL within the IL/PUA samples, as it will be analysed in detail latter.

\subsection{Mechanical and electrical properties}


The mechanical characterization of the IL/PUA films was performed by stress vs. strain measurements in tensile mode (Figure 7a) and the corresponding elastic modulus (Figure 7b) and strain at breaks (Table 3) were evaluated.
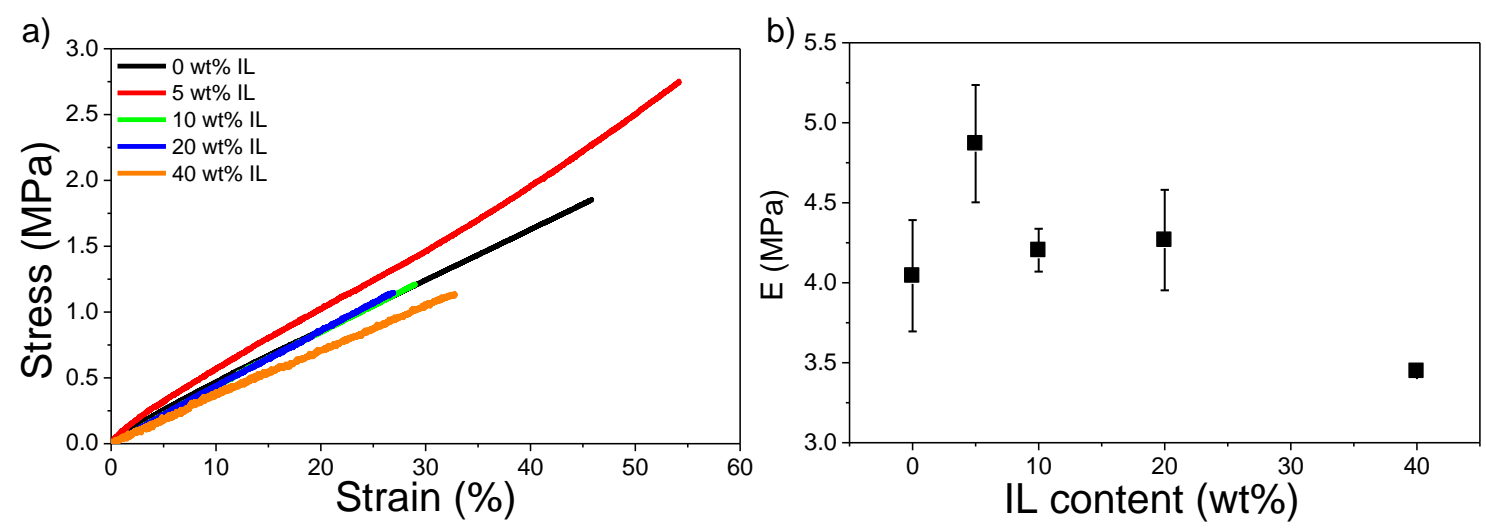

C)
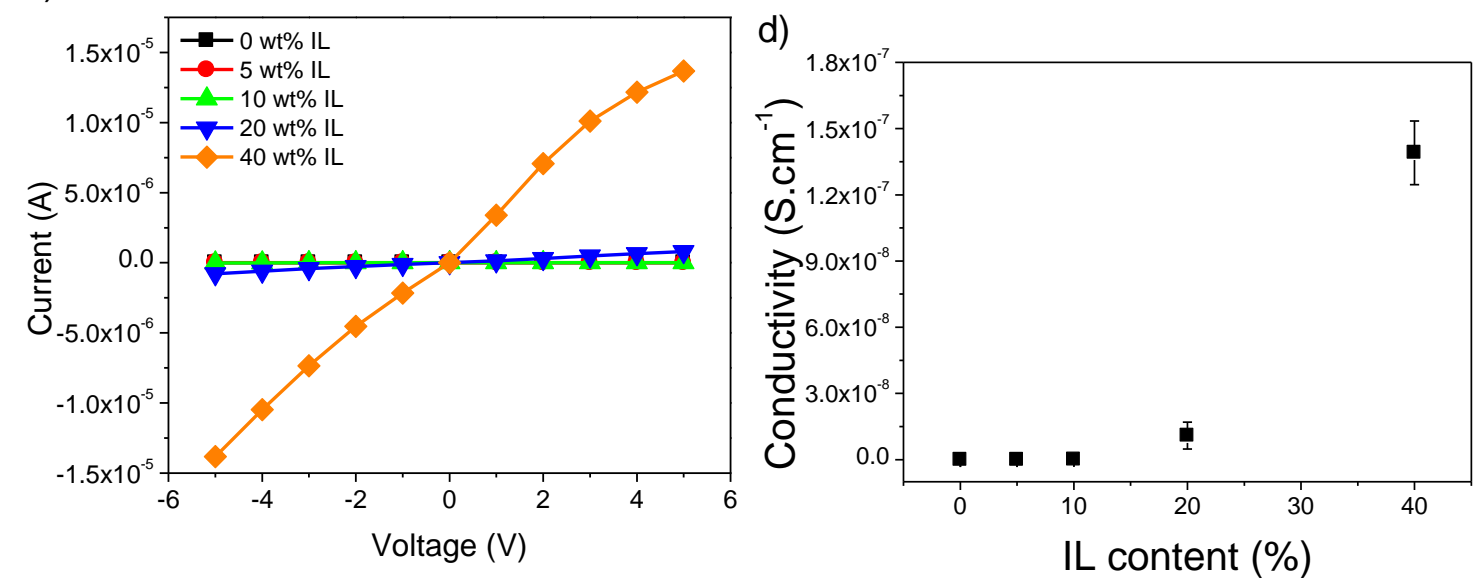

Figure 7. Stress vs. strain mechanical characteristic curves (a) and Young modulus (b) for neat PUA and for IL/PUA samples containing different [Bmim $]_{2}\left[\mathrm{NiCl}_{4}\right]$ contents. I-V curves $(\mathrm{c})$ and electrical conductivity $(d)$ for the same samples.

According to Figure 7a, all samples exhibit a linear elastic response up to a breaking point. The maximum strain for the PUA film is $\sim 45 \%$ decreasing down to $\sim 27 \%$ for the IL/PUA film with a $[\mathrm{Bmim}]_{2}\left[\mathrm{NiCl}_{4}\right]$ content of $20 \mathrm{wt}$.\%. The Young's modulus (Figure $7 \mathrm{~b}$ ) has a value of $4.04 \pm 0.35 \mathrm{MPa}$ for the PUA photoresin film and slightly increase to $4.87 \pm 0.37 \mathrm{MPa}$ for the $5 \mathrm{wt}$. \% IL composite. However, for concentrations higher than 5 wt.\%, a reduction in the Young modulus is observed, being $4.20 \pm 0.13$ $\mathrm{MPa}$ and $4.27 \pm 0.31 \mathrm{MPa}$ for the composites containing 10 and 20 wt.\% of $[\mathrm{Bmim}]_{2}\left[\mathrm{NiCl}_{4}\right]$, respectively. The IL/PUA film with $40 \mathrm{wt} . \%$ of $[\mathrm{Bmim}]_{2}\left[\mathrm{NiCl}_{4}\right]$ shows a Young modulus of $3.45 \pm 0.02 \mathrm{MPa}$. The decrease in the Young modulus is mainly attributed to the plasticizing effect of the $[\mathrm{Bmim}]_{2}\left[\mathrm{NiCl}_{4}\right]$ as well as to the observed 
morphology variations increasing $[\mathrm{Bmim}]_{2}\left[\mathrm{NiCl}_{4}\right]$ content, appreciated in the SEM images [53].

Attending to the elongation level of the material, the addition of IL increases the maximum elongation of the materials for the lower IL contents being $45.8 \pm 3.2 \%$ for neat PUA and $54.3 \pm 4.4 \%$ for the 5 wt.\% sample. When higher amounts of IL are added, the maximum elongation decreases down to $27.0 \pm 2.5 \%$ for the 20 wt.\% sample. As shown before, the addition of IL induces variations on the morphology of the obtained polymer hybrids resulting in increasingly porous structures and, as consequence, the materials show lower levels of stretchability [54]. Interestingly, all films present bending ability and do not become fragile with the introduction of different amounts of the IL, being therefore suitable materials for flexible applications.

The electrical properties of the samples are shown in Figure 7c and d. Figure 7c shows the characteristic I-V curves and the corresponding volume electrical conductivity of the films is presented in Figure 7d.

All samples exhibit a typical I-V linear behavior independent of the IL content, with the slope increasing with increasing IL content (Figure 7c). The electrical conductivity of the samples (Equation 3), shows a strong increase with increasing IL content (Figure $7 \mathrm{~d}$ ), the electrical conductivity of the PUA film being around $2.92 \times 10^{-12} \mathrm{~S} \cdot \mathrm{m}^{-1}$ and the highest electrical conductivity being obtained for the sample with $40 \mathrm{wt} . \%$

[Bmim $]_{2}\left[\mathrm{NiCl}_{4}\right]$ IL content: $5.51 \times 10^{-6} \mathrm{~S} \cdot \mathrm{m}^{-1}$. This increase results from the ionic characteristics of the ILs and to ion-dipole interactions, that occurs between the IL and the PUA being the electrical conductivity governed by the increase in the number and mobility of the ions, ionic charge and viscosity of the $\left[\mathrm{Bmim}_{2}\left[\mathrm{NiCl}_{4}\right][55]\right.$. By increasing the $[\mathrm{Bmim}]_{2}\left[\mathrm{NiCl}_{4}\right]$ concentration in the polymeric matrix, the ion transport and dissociation of IL is promoted, increasing the number of ionic carriers. Further, it has been reported that the IL-polymer interaction may decrease as the IL content increases, promoting a more rapid ionic transport [32].

\subsection{Temperature-activated humidity-sensitive materials}

\subsubsection{UV-Vis characterization}

The thermochromic effect of the PUA/[Bmim $]_{2}\left[\mathrm{NiCl}_{4}\right]$ films was evaluated by UV-Vis spectroscopy at different temperatures (Figure 8). Figure 8a shows the UV-Vis spectra 
for PUA/[Bmim $]_{2}\left[\mathrm{NiCl}_{4}\right]$ composite with $20 \mathrm{wt} \%$ of $[\mathrm{Bmim}]_{2}\left[\mathrm{NiCl}_{4}\right]$ content in the temperature range from 30 to $70{ }^{\circ} \mathrm{C}$. Figure $8 \mathrm{~b}$ shows the UV-Vis curves for the composites with different IL contents at $70{ }^{\circ} \mathrm{C}$.

a)

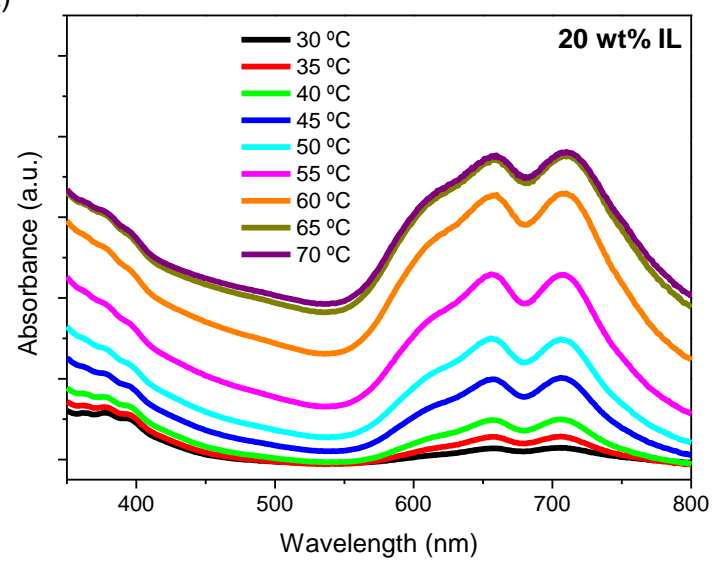

b)

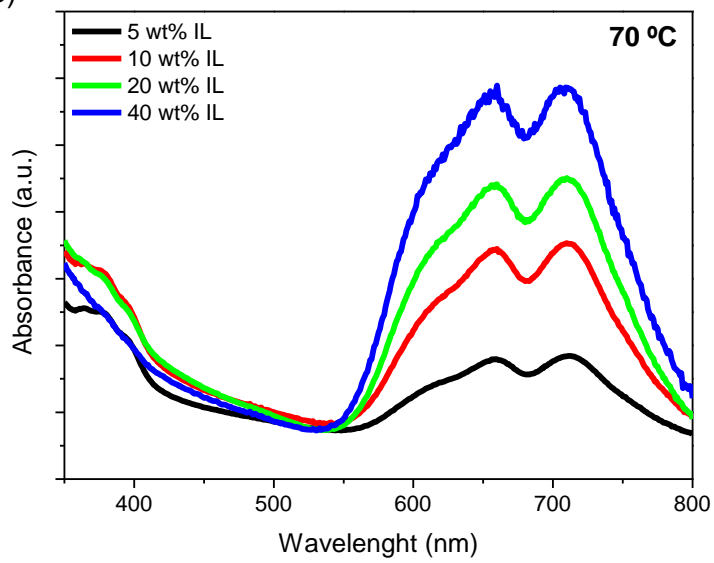

Figure 8. UV-Vis spectra for the IL/PUA samples containing $20 \mathrm{wt} . \%$ of [ $\mathrm{Bmim}_{2}\left[\mathrm{NiCl}_{4}\right]$ content in the temperature range from 30 to $70^{\circ} \mathrm{C}(a)$ and $U V$-Vis curves for the different samples at $70^{\circ} \mathrm{C}(b)$.

Upon the processing, and independently of the IL content, the films are colourless, changing their colour to blue upon the heating up to $70^{\circ} \mathrm{C}$, being the colour change a reversible and temperature-dependent process.

Figure 8a shows that the increase in temperature from 30 to $70{ }^{\circ} \mathrm{C}$ induces the appearance and subsequent increase of two absorption bands at 660 and $710 \mathrm{~nm}$. Comparing these two peaks among them, similar intensity and shape is obtained regardless of the temperature. Furthermore, this process is observed for all IL/PUA samples, independently of the $[\mathrm{Bmim}]_{2}\left[\mathrm{NiCl}_{4}\right]$ content, as it is shown in the supporting information (Figure S1), reaching maximum absorption at temperatures between 60 and $70{ }^{\circ} \mathrm{C}$ in all cases. In addition, an increase of the IL content from 5 to $40 \mathrm{wt} . \%$ induces an increase in the absorption bands, as presented in Figure $8 \mathrm{~b}$.

The appearance of the two absorption bands with increasing temperature indicates colour change of the films from colourless to blue. As indicated, the absorption peaks appear at wavelengths between 600 and $750 \mathrm{~nm}$, ascribed to the blue region of the UVVis spectrum. In addition, these peaks reach a maximum absorption value that corresponds to the most intense blue colour obtained in the films and this colour is dependent on the IL content of the composite, increasing the peak intensity, and in this sense the colour intensity, with the IL content. The observed peaks of similar intensities 
are related to the $\left[\mathrm{NiCl}_{4}\right]^{2-}$ complex in its tetrahedral conformation [47], being thus responsible for the colour variation. Therefore, the colour change of the composites is related to the modification of the coordination reaction [32].

\subsubsection{Temperature-humidity-colour change characterization}

As the composites are thermally and humidity responsive, they show a strong potential for smart and multifunctional coatings and/or sensing materials. Figure 9 shows the evolution of the colour with varying relative humidity $(\mathrm{RH})$ at constant temperature, and with varying temperature at constant humidity.

a)

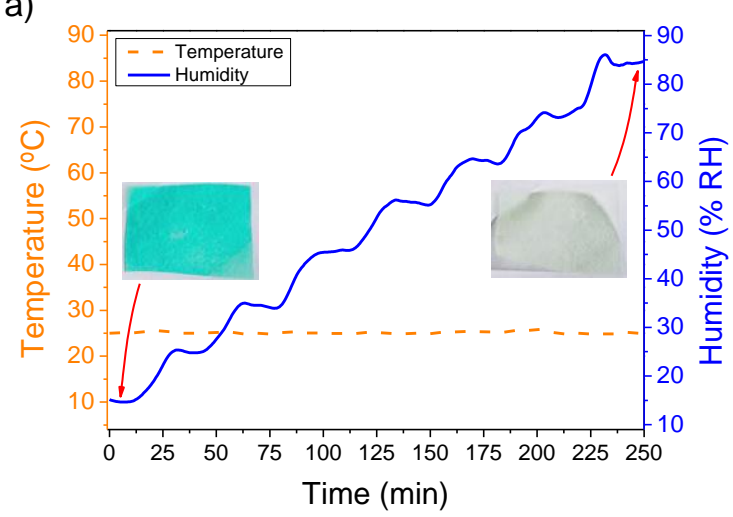

b)

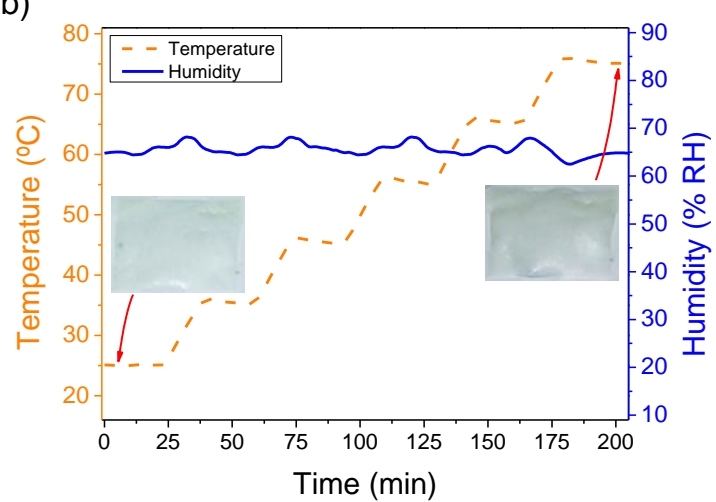

Figure 9. Colour variation of the films (initial and final state) with increasing relative humidity at constant temperature of $25{ }^{\circ} \mathrm{C}(\mathrm{a})$ and with increasing temperature at constant relative humidity of $60 \%(b)$.

Attending to Figure 9a and the corresponding supplementary Video 1, as the relative humidity increases, keeping the temperature constant, the film remains completely blue until $55 \%$ of RH. At this moment, the film starts to change its colour to a lighter blue. When a RH of $75 \%$ is reached, the film becomes colourless, defining the "range of colour change" from 55 to $75 \%$ of RH.

These results also indicate a reversible response of the film in which blue films can recover the transparency/whitish colour at room temperature, confirming the reversible thermochromism, which is explained by an abrupt change in the chemical structure as indicated in section 3.5.3 [56].

Further, when the $\mathrm{RH}$ increases, keeping the temperature constant (Figure $\mathrm{S} 2 \mathrm{a}$ and Video 2 of the supporting information), the film remains completely blue. When a RH of $40 \%$ is achieved, the film starts to change its colour to a lighter blue (similarly to the first test at room temperature). Finally, when a RH of $55 \%$ is reached, the film becomes 
colourless, defining the range of colour change from 40 to $55 \% \mathrm{RH}$. Thus, temperature has a strong influence on the range of colour change, a decrease from $55 \%$ to $40 \%$ of $\mathrm{RH}$ being observed for the beginning of the colour change when the tests are performed at constant temperature of $25^{\circ} \mathrm{C}$ or $45^{\circ} \mathrm{C}$, respectively.

When the temperature is maintained at $10^{\circ} \mathrm{C}$ (Figure S2b and Video 3 of the supporting information), a similar result is obtained. However, in this case, the film has not turned completely colourless at the end of the experiment, remaining slightly blue. In addition, the colour change begins at higher $\mathrm{RH}$, around $65 \%$ of $\mathrm{RH}$, than in the previous test indicating that the water absorption (hydration of $[\mathrm{Bmim}]_{2}\left[\mathrm{NiCl}_{4}\right]$ ) is slower than when temperature is $25^{\circ} \mathrm{C}$ or $45^{\circ} \mathrm{C}$. Thus, the variation on the moisture absorption by the ILs with temperature and RH is confirmed [57]. The ILs structure (cation and anion type or cation alkyl chain length) and external factors (relative humidity, temperature or impurities) have an influence on the hydration of ILs [58] demonstrating that is a process sensitive to and stimulated by temperature [59].

Figure $9 \mathrm{~b}$ and supporting information Video 4 show that the colourless sample does not undergo any change during the heating process under the defined test conditions (temperature variation from $25^{\circ} \mathrm{C}$ to $75^{\circ} \mathrm{C}$ under constant $\mathrm{RH}$ of $60 \%$ ). Thus, when there is enough humidity, the temperature has not influence for the colouring process.

Finally, as shown in Figure S2c and Video 5 of the supporting information, when the temperature reaches $65^{\circ} \mathrm{C}$, the film begins to undergo a colour change. This result indicates that the water evaporation occurs when temperature reaches the mentioned value and, as a result, a hydrothermochromatic coordination reaction occurs (from the colourless octahedral complex to the blue tetrahedral). Thus, when humidity is lower than $55 \%$, temperature induces water evaporation and, therefore, substitution of water molecules by $\mathrm{Cl}^{-}$atoms in the $\mathrm{Ni}$ (II) complex [60].

Thus, it is shown that the chromic phenomenon is humidity governed as at each temperature the humidity sets the colour change (directly dependence on the humidity of the system), and is thermally activated as the humidity limit value for the colour change depends on the temperature of the system. Thus, these humidity hybrid sensing materials present a temperature limit of $10{ }^{\circ} \mathrm{C}$ below which colour change is not clearly observed. At room temperature, colour change occurs at $55 \%$ of $\mathrm{RH}$, setting this value as limit for thermochromic effect upon temperature variation. 


\section{$\underline{\text { 3.5.3. Colour change mechanism }}$}

The colour changes observed by both the UV-Vis (Figures 8 and S1) and the climate chamber assays (Figures 9 and S2), are related to the $\left[\mathrm{NiCl}_{4}\right]^{2-}$ complex in its tetrahedral conformation [47]. Therefore, the colour change of the films is related to the modification of the coordination reaction as reported in Scheme 1a [32].

a)

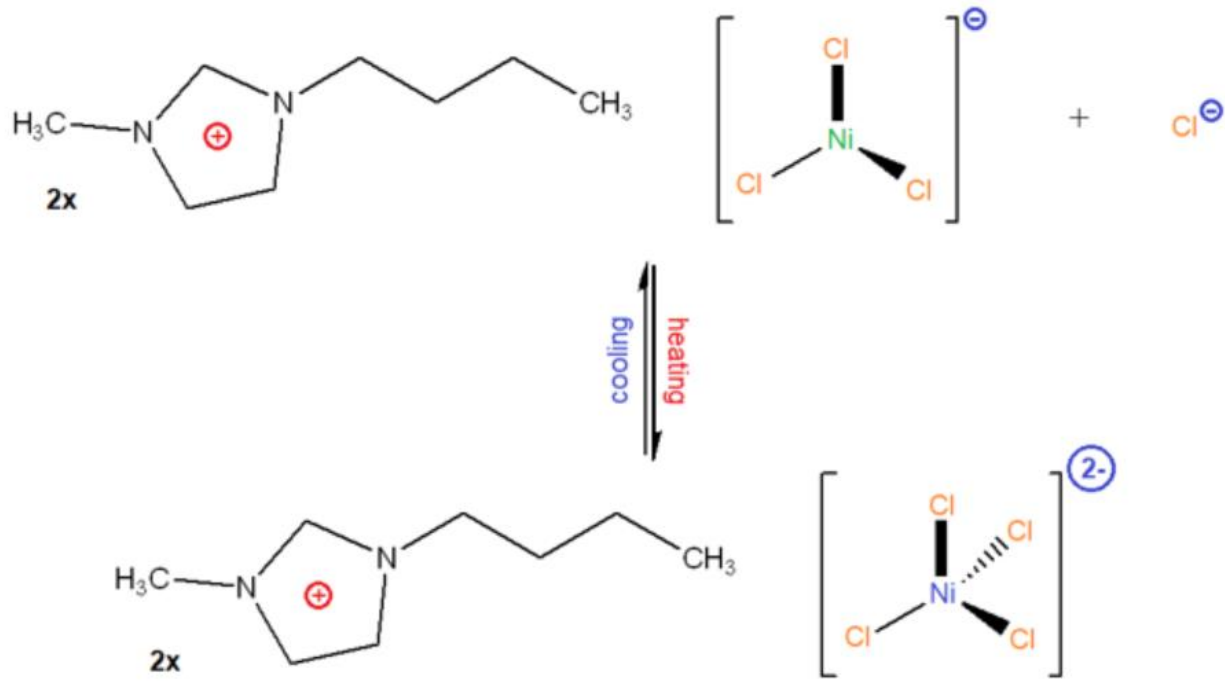

b)

$\left.\left[\mathrm{Ni}\left(\mathrm{H}_{2} \mathrm{O}\right)_{6}\right]_{(a q)}^{2+}+4 \mathrm{Cl}_{(a q)}^{-} \underset{\text { cooling }}{\rightleftharpoons} \underset{\text { heating }}{\rightleftharpoons} \mathrm{NiCl}_{4}\right]_{(a q)}^{2-}+4 \mathrm{H}_{2} \mathrm{O}_{(l)}$

Scheme 1. Chemical modifications occurring during the heating and cooling process of the $[\mathrm{Bmim}]_{2}\left[\mathrm{NiCl}_{4}\right]$ ionic liquid (a) and changes in the coordination number of $\mathrm{Ni}(\mathrm{II})$ from octahedral to tetrahedral structure (b). Reproduced with permission [32]. Copyright 2019, ACS Publications.

$[\mathrm{Bmim}]_{2}\left[\mathrm{NiCl}_{4}\right]$ is a hygroscopic salt capable of absorbing water molecules from ambient humidity. The afore discussed experiments show that the observed colour change is attributed to an absorption/dehydration process of the IL [32]. The coordination number of $\mathrm{Ni}$ (II) in the IL structure undergoes a change, varying its structure form tetrahedral (blue colour) to octahedral (not colour) without change in the cationic structure (see Scheme 1a) [61]. At room temperature, the $\mathrm{Cl}^{-}$ions of the nickel complex are replaced by water molecules from ambient humidity as a result of $\mathrm{H}$-bond interactions with the $\mathrm{IL}$ anion $\left[\mathrm{NiCl}_{4}\right]^{2-}[47]$, corroborating the DSC endothermic peak results [51] (section 3.3). Therefore, the colouring process is dependent on the environmental humidity as demonstrated in the scheme $1 \mathrm{~b}$. 
Therefore, the thermochromic effect of the IL/PUA composite is an effect due to the water absorption/dehydration of the $\left[\mathrm{NiCl}_{4}\right]^{2-}$, i.e. a change on the coordination number of the $\mathrm{Ni}(\mathrm{II})$ from octahedral to tetrahedral depending on the hydrated $\left(\left[\mathrm{Ni}\left(\mathrm{H}_{2} \mathrm{O}\right)_{6}\right]^{2+}\right)$ or dehydrated $\left(\left[\mathrm{NiCl}_{4}\right]^{2-}\right)$ state.

\section{Conclusions}

Flexible electronic devices and smart and multifunctional coatings are one of the cornerstones of the current technological advances. In this work, a flexible and costeffective dual humidity and temperature sensor and/or coating material has been successfully developed. After the incorporation of ionic liquid in a UV-curable polymer matrix, a porous network structure is obtained without relevant chemical changes neither in the IL or in the polymer matrix. In addition, the incorporation of the IL slightly influences the UV curing process of the polymer obtaining in all cases a polymer curing conversion of $88 \%$ or above. Further, the inclusion of the IL influences the electrical and mechanical properties of the samples for the higher IL contents obtaining an increase in the electrical conductivity and a decrease on the Young modulus.

Thermochromic effect was observed even at low IL loads. It was observed that humidity has a strong influence in the thermochromic effect up to $55 \% \mathrm{RH}$ and that this process is thermally influenced. This effect is due to the water absorption/dehydration of $\left[\mathrm{NiCl}_{4}\right]^{2-}$, which is related to a variation in the coordination number of the $\mathrm{Ni}$ (II) from octahedral to tetrahedral depending the hydrated $\left(\left[\mathrm{Ni}\left(\mathrm{H}_{2} \mathrm{O}\right)_{6}\right]^{2+}\right)$ or dehydrated $\left(\left[\mathrm{NiCl}_{4}\right]^{2-}\right.$ ) state.

Thus, the present work demonstrated the suitability of UV curable hybrid materials for smart and multifunctional coatings processable by additive manufacturing technologies, paving the way to cost-effective sensing coatings with a low carbon footprint due to it solvent-less process.

\section{Acknowledgements}

The authors acknowledge the FCT (Fundação para a Ciência e Tecnologia) for financial support under the framework of Strategic Funding grants UID/FIS/04650/2020, UID/EEA/04436/2020 and UID/QUI/0686/2020 and project no. PTDC/FISMAC/28157/2017. The authors thank funding by the Spanish State Research Agency 
(AEI) and the European Regional Development Fund (ERFD) through the project PID2019-106099RB-C43 / AEI / 10.13039/501100011033 and under the Operational Programme "Competitiveness and Internationalization" - Research and Development (R\&D) and Innovation to SMEs - R\&D Individuals Projects, grant agreement number 038397. M. S. also acknowledge the National Research grant "Juan de la Cierva" FJCI2017-31761. Financial support from the Basque Government Industry and Education Departments under the ELKARTEK, HAZITEK and PIBA programs is also acknowledged. LCF and DCM also thank the grant SFRH/BD/145345/2019 and SFRH/BPD/121526/2016, respectively.Technical and human support provided by SGIker (UPV/EHU, MICINN, GV/EJ, EGEF and ESF) is gratefully acknowledged. 


\section{References}

[1] A. Endruweit, M.S. Johnson, A.C. Long, Curing of Composite Components by Ultraviolet Radiation: A Review, Polym. Compos. 27 (2006) 119-128. https://doi.org/10.1002/pc.20166.

[2] P. Xiao, J. Zhang, F. Dumur, M.A. Tehfe, F. Morlet-Savary, B. Graff, D. Gigmes, J.P. Fouassier, J. Lalevée, Visible light sensitive photoinitiating systems: Recent progress in cationic and radical photopolymerization reactions under soft conditions, Prog. Polym. Sci. 41 (2015) 32-66. https://doi.org/10.1016/j.progpolymsci.2014.09.001.

[3] C. Mendes-Felipe, J. Oliveira, I. Etxebarria, J.L. Vilas-Vilela, S. LancerosMendez, State-of-the-Art and Future Challenges of UV Curable Polymer-Based Smart Materials for Printing Technologies, Adv. Mater. Technol. 4 (2019) 1-16. https://doi.org/10.1002/admt.201800618.

[4] I. Gibson, D. Rosen, B. Stucker, Additive Manufacturing Technologies: 3D Printing, Rapid Prototyping, and Direct Digital Manufacturing, Second Edi, Springer, 2015. https://doi.org/10.2495/SDP-V9-N5-658-668.

[5] H. Lasi, P. Fettke, H.G. Kemper, T. Feld, M. Hoffmann, Industry 4.0, Bus. Inf. Syst. Eng. 6 (2014) 239-242. https://doi.org/10.1007/s12599-014-0334-4.

[6] E. Oztemel, S. Gursev, Literature review of Industry 4.0 and related technologies, J. Intell. Manuf. 31 (2020) 127-182. https://doi.org/10.1007/s10845-018-1433-8.

[7] M.L. Kolhe, T. Shailesh, M.C. Trivedi, K.K. Mishra, Advances in Data and Information Sciences Proceedings of ICDIS 2019, Springer, 2020. https://doi.org/10.1007/978-981-15-0694-9_34.

[8] Y. Xu, X. Wu, X. Guo, B. Kong, M. Zhang, X. Qian, S. Mi, W. Sun, The Boom in 3D-Printed Sensor Technology, China, 2017. https://doi.org/10.3390/s17051166.

[9] S. Díaz, J.B. Stephenson, M.A. Labrador, Use of wearable sensor technology in gait, balance, and range of motion analysis, Appl. Sci. 10 (2020). https://doi.org/10.3390/app10010234.

[10] L.T. Ng, J.T. Guthrie, Y.J. Yuan, H. Zhao, UV-cured natural polymer-based 
membrane for biosensor application, J. Appl. Polym. Sci. 79 (2001) 466-472. https://doi.org/10.1002/1097-4628(20010118)79:3<466::AID-APP90>3.0.CO;2F.

[11] C. Mendes-Felipe, J. Oliveira, P. Costa, L. Ruiz-Rubio, A. Iregui, A. González, J.L. Vilas, S. Lanceros-Mendez, Stimuli responsive UV cured polyurethane acrylated/carbon nanotube composites for piezoresistive sensing, Eur. Polym. J. 120 (2019) 109226. https://doi.org/10.1016/j.eurpolymj.2019.109226.

[12] O. Jifei, D. Gershon, C. Chin-Yi, H. Felix, W. Karl, H. Ishii, Cilllia - 3D Printed Micro-Pillar Structures for Surface Texture, Actuation and Sensing, Des. New Mater. Manuf. Tech. (2016) 5753-5764. https://doi.org/10.2307/j.ctt1n7qkg7.29.

[13] D.I. Woodward, C.P. Purssell, D.R. Billson, D.A. Hutchins, S.J. Leigh, Additively-manufactured piezoelectric devices, Phys. Status Solidi Appl. Mater. Sci. 212 (2015) 2107-2113. https://doi.org/10.1002/pssa.201532272.

[14] P. Maillard, A. Heinrich, 3D printed freeform optical sensors for metrology application, Opt. Syst. Des. 2015 Opt. Fabr. Testing, Metrol. V. 9628 (2015) 96281J. https://doi.org/10.1117/12.2191280.

[15] A. Wickberg, J.B. Mueller, Y.J. Mange, J. Fischer, T. Nann, M. Wegener, Threedimensional micro-printing of temperature sensors based on up-conversion luminescence, Appl. Phys. Lett. 106 (2015) 1-5. https://doi.org/10.1063/1.4916222.

[16] M.E. Staymates, W.A. MacCrehan, J.L. Staymates, R.R. Kunz, T. Mendum, T.H. Ong, G. Geurtsen, G.J. Gillen, B.A. Craven, Biomimetic Sniffing Improves the Detection Performance of a 3D Printed Nose of a Dog and a Commercial Trace Vapor Detector, Sci. Rep. 6 (2016) 1-10. https://doi.org/10.1038/srep36876.

[17] C.C. Okpala, Nanocomposites - An Overview, 8 (2013) 17-23.

[18] X. Wang, M. Jiang, Z. Zhou, J. Gou, D. Hui, 3D printing of polymer matrix composites: A review and prospective, Compos. Part B Eng. 110 (2017) 442458. https://doi.org/10.1016/j.compositesb.2016.11.034.

[19] J.W. Stansbury, M.J. Idacavage, 3D printing with polymers: Challenges among expanding options and opportunities, Dent. Mater. 32 (2016) 54-64. 
https://doi.org/10.1016/j.dental.2015.09.018.

[20] J. Saroia, Y. Wang, Q. Wei, M. Lei, X. Li, Y. Guo, K. Zhang, A review on 3D printed matrix polymer composites: its potential and future challenges, Int. J. Adv. Manuf. Technol. 106 (2020) 1695-1721. https://doi.org/10.1007/s00170019-04534-z.

[21] J.Z. Manapat, Q. Chen, P. Ye, R.C. Advincula, 3D Printing of Polymer Nanocomposites via Stereolithography, Macromol. Mater. Eng. 302 (2017) 1-13. https://doi.org/10.1002/mame.201600553.

[22] T.A. Campbell, O.S. Ivanova, 3D printing of multifunctional nanocomposites, Nano Today. 8 (2013) 119-120. https://doi.org/10.1016/j.nantod.2012.12.002.

[23] D.M. Correia, L.C. Fernandes, P.M. Martins, C. García-Astrain, C.M. Costa, J. Reguera, S. Lanceros-Méndez, Ionic Liquid-Polymer Composites: A New Platform for Multifunctional Applications, Adv. Funct. Mater. 30 (2020) 1-43. https://doi.org/10.1002/adfm.201909736.

[24] Z. Lei, B. Chen, Y.M. Koo, D.R. Macfarlane, Introduction: Ionic Liquids, Chem. Rev. 117 (2017) 6633-6635. https://doi.org/10.1021/acs.chemrev.7b00246.

[25] S. Zhang, Q. Zhang, Y. Zhang, Z. Chen, M. Watanabe, Y. Deng, Beyond solvents and electrolytes: Ionic liquids-based advanced functional materials, Prog. Mater. Sci. 77 (2016) 80-124. https://doi.org/10.1016/j.pmatsci.2015.10.001.

[26] C. Guerrero-Sanchez, T. Erdmenger, T. Lara-Ceniceros, E. Jimenez-Regalado, U.S. Schubert, Chapter 10 - Smart materials based on ionic liquids: The magnetorheological fluid case, in: Ion. Liq. From Knowl. to Appl., ACS Symposium Series, 2009: pp. 147-155. https://doi.org/10.1021/bk-20091030.ch010.

[27] B. Ziõłkowski, Z. Ates, S. Gallagher, R. Byrne, A. Heise, K.J. Fraser, D. Diamond, Mechanical properties and UV curing behavior of poly $(\mathrm{N}-$ Isopropylacrylamide) in phosphonium-based ionic liquids, Macromol. Chem. Phys. 214 (2013) 787-796. https://doi.org/10.1002/macp.201200616.

[28] C. Gerbaldi, J.R. Nair, S. Ahmad, G. Meligrana, R. Bongiovanni, S. Bodoardo, 
N. Penazzi, UV-cured polymer electrolytes encompassing hydrophobic room temperature ionic liquid for lithium batteries, J. Power Sources. 195 (2010) 1706-1713. https://doi.org/10.1016/j.jpowsour.2009.09.047.

[29] N.A. Bakhtina, U. Loeffelmann, N. MacKinnon, J.G. Korvink, Two-Photon Nanolithography Enhances the Performance of an Ionic Liquid-Polymer Composite Sensor, Adv. Funct. Mater. 25 (2015) 1683-1693. https://doi.org/10.1002/adfm.201404370.

[30] A.R. Schultz, P.M. Lambert, N.A. Chartrain, D.M. Ruohoniemi, Z. Zhang, C. Jangu, M. Zhang, C.B. Williams, T.E. Long, 3D printing phosphonium ionic liquid networks with mask projection microstereolithography, ACS Macro Lett. 3 (2014) 1205-1209. https://doi.org/10.1021/mz5006316.

[31] K. Chen, J. Zhou, F. Ge, R. Zhao, C. Wang, Smart UV-curable fabric coatings with self-healing ability for durable self-cleaning and intelligent oil/water separation, Colloids Surfaces A Physicochem. Eng. Asp. 565 (2019) 86-96. https://doi.org/10.1016/j.colsurfa.2019.01.003.

[32] L.C. Fernandes, D.M. Correia, C. García-Astrain, N. Pereira, M. Tariq, J.M.S.S. Esperança, S. Lanceros-Méndez, Ionic-Liquid-Based Printable Materials for Thermochromic and Thermoresistive Applications, ACS Appl. Mater. Interfaces. 11 (2019) 20316-20324. https://doi.org/10.1021/acsami.9b00645.

[33] L. Yu, G.Z. Chen, Cryo-solvatochromism in ionic liquids, RSC Adv. 4 (2014) 40281-40285. https://doi.org/10.1039/c4ra08116a.

[34] G. Perez, V.R. Allegro, M. Corroto, A. Pons, A. Guerrero, Smart reversible thermochromic mortar for improvement of energy efficiency in buildings, Constr. Build. Mater. 186 (2018) 884-891. https://doi.org/10.1016/j.conbuildmat.2018.07.246.

[35] H. Kim, Y. Kim, K.S. Kim, H.Y. Jeong, A.R. Jang, S.H. Han, D.H. Yoon, K.S. Suh, H.S. Shin, T. Kim, W.S. Yang, Flexible thermochromic window based on hybridized VO2/graphene, ACS Nano. 7 (2013) 5769-5776. https://doi.org/10.1021/nn400358x.

[36] M.G. Baron, M. Elie, Temperature sensing using reversible thermochromic polymeric films, Sensors Actuators, B Chem. 90 (2003) 271-275. 
https://doi.org/10.1016/S0925-4005(03)00045-5.

[37] L.C. Fernandes, D.M. Correia, N. Pereira, C.R. Tubio, S. Lanceros-Méndez, Highly Sensitive Humidity Sensor Based on Ionic Liquid-Polymer Composites, ACS Appl. Polym. Mater. 1 (2019) 2723-2730.

https://doi.org/10.1021/acsapm.9b00675.

[38] X. Ni, J. Luo, R. Liu, X. Liu, A novel flexible UV-cured carbon nanotube composite film for humidity sensing, Sensors Actuators, B Chem. 297 (2019). https://doi.org/10.1016/j.snb.2019.126785.

[39] X. Lv, Y. Li, P. Li, M. Yang, A resistive-type humidity sensor based on crosslinked polyelectrolyte prepared by UV irradiation, Sensors Actuators, B Chem. 135 (2009) 581-586. https://doi.org/10.1016/j.snb.2008.10.008.

[40] N.B. Cho, T.H. Lim, Y.M. Jeon, M.S. Gong, Inkjet printing of polymeric resistance humidity sensor using UV-curable electrolyte inks, Macromol. Res. 16 (2008) 149-154. https://doi.org/10.1007/BF03218844.

[41] C. Decker, New developments in UV radiation curing of protective coatings, Surf. Coatings Int. Part B Coatings Trans. 88 (2005) 9-17. https://doi.org/10.1007/BF02699702.

[42] C. Zhong, T. Sasaki, A. Jimbo-Kobayeshi, E. Fujiwara, A. Kobayashi, M. Tada, Y. Iwasawa, Syntheses, structures, and properties of a series of metal ioncontaining dialkylimidazolium ionic liquids, Bull. Chem. Soc. Jpn. 80 (2007) 2365-2374. https://doi.org/10.1246/bcsj.80.2365.

[43] M.B. Meredith, C.H. McMillen, J.T. Goodman, T.P. Hanusa, Ambient temperature imidazolium-based ionic liquids with tetrachloronickelate(II) anions, Polyhedron. 28 (2009) 2355-2358. https://doi.org/10.1016/j.poly.2009.04.037.

[44] O. Llorente, M.J. Fernández-Berridi, A. González, L. Irusta, Study of the crosslinking process of waterborne UV curable polyurethane acrylates, Prog. Org. Coatings. 99 (2016) 437-442. https://doi.org/10.1016/j.porgcoat.2016.06.020.

[45] C. Mendes-Felipe, T. Rodrigues-Marinho, J.L. Vilas, S. Lanceros-Mendez, UV curable nanocomposites with tailored dielectric response, Polymer (Guildf). 196 
(2020). https://doi.org/10.1016/j.polymer.2020.122498.

[46] C. Mendes-Felipe, J.C. Barbosa, S. Gonçalves, N. Pereira, C.M. Costa, J.L. Vilas-Vilela, S. Lanceros-Mendez, High dielectric constant UV curable polyurethane acrylate/indium tin oxide composites for capacitive sensing, Compos. Sci. Technol. 199 (2020). https://doi.org/10.1016/j.compscitech.2020.108363.

[47] X. Wei, L. Yu, D. Wang, X. Jin, G.Z. Chen, Thermo-solvatochromism of chloronickel complexes in 1-hydroxyalkyl-3-methyl-imidazolium cation based ionic liquids, Green Chem. 10 (2008) 296-30. https://doi.org/10.1039/b715763k.

[48] X. Gong, J. Zhang, S. Jiang, Ionic liquid-induced nanoporous structures of polymer films, Chem. Commun. 56 (2020) 3054-3057. https://doi.org/10.1039/c9cc08768k.

[49] P.K. Behera, K.M. Usha, P.K. Guchhait, D. Jehnichen, A. Das, B. Voit, N.K. Singha, A novel ionomeric polyurethane elastomer based on ionic liquid as crosslinker, RSC Adv. 6 (2016) 99404-99413. https://doi.org/10.1039/c6ra21650a.

[50] R. Fernández De Luis, M.K. Urtiaga, J.L. Mesa, K. Vidal, L. Lezama, T. Rojo, M.I. Arriortua, Short-Range and long-range magnetic ordering, in third generation brannerite type inorganic-organic vanadates: [\{Mn(Bpy) $\}(\mathrm{VO} 3)$ $2] \approx(\mathrm{H} 2 \mathrm{O}) 1.16$ and $[\{\mathrm{Mn}(\mathrm{Bpy}) 0.5\}(\mathrm{VO} 3) 2] \approx(\mathrm{H} 2 \mathrm{O}) 0.62$, Chem. Mater. 22 (2010) 5543-5553. https://doi.org/10.1021/cm1015433.

[51] R. Fernández De Luis, J. Orive, E.S. Larrea, M.K. Urtiaga, M.I. Arriortua, Reversible solid-state transformation in $\{\mathrm{Ni} 2(\mathrm{H} \mathrm{2O}) 2(\mathrm{Bpa}) 2\}(\mathrm{V} 6 \mathrm{O} 17)$ proved by synchrotron radiation: Color and magnetic properties change, Cryst. Growth Des. 14 (2014) 658-670. https://doi.org/10.1021/cg401540s.

[52] L. Liu, Z. Zheng, C. Gu, X. Wang, The poly(urethane-ionic liquid)/multi-walled carbon nanotubes composites, Compos. Sci. Technol. 70 (2010) 1697-1703. https://doi.org/10.1016/j.compscitech.2010.06.007.

[53] D.M. Correia, J.C. Barbosa, C.M. Costa, P.M. Reis, J.M.S.S. Esperança, V. De Zea Bermudez, S. Lanceros-Méndez, Ionic Liquid Cation Size-Dependent Electromechanical Response of Ionic Liquid/Poly(vinylidene fluoride)-Based 
Soft Actuators, J. Phys. Chem. C. 123 (2019) 12744-12752.

https://doi.org/10.1021/acs.jpcc.9b00868.

[54] A. Reizabal, R. Gonçalves, A. Fidalgo-Marijuan, C.M. Costa, L. Pérez, J.L. Vilas, S. Lanceros-Mendez, Tailoring silk fibroin separator membranes pore size for improving performance of lithium ion batteries, J. Memb. Sci. 598 (2020). https://doi.org/10.1016/j.memsci.2019.117678.

[55] J.C. Dias, M.S. Martins, S. Ribeiro, M.M. Silva, J.M.S.S. Esperança, C. Ribeiro, G. Botelho, C.M. Costa, S. Lanceros-Mendez, Electromechanical actuators based on poly(vinylidene fluoride) with [N1 $1112(\mathrm{OH})][\mathrm{NTf} 2]$ and [C2mim] [C2SO4], J. Mater. Sci. 51 (2016) 9490-9503. https://doi.org/10.1007/s10853-016-0193-0.

[56] K. Sone, Y. Fukuda, Chapter F - Thermochromism of Transition Metal Complexes in the Solid State, in: Inorg. Thermochromism, Springer-Verlag, 1987: pp. 104-131. https://doi.org/10.1007/978-3-642-51017-5_6.

[57] Y. Chen, X. Gao, X. Liu, G. Ji, L. Fu, Y. Yang, Q. Yu, W. Zhang, X. Xue, Water collection from air by ionic liquids for efficient visible-light-driven hydrogen evolution by metal-free conjugated polymer photocatalysts, Renew. Energy. 147 (2020) 594-601. https://doi.org/10.1016/j.renene.2019.09.029.

[58] Y. Cao, Y. Chen, X. Sun, Z. Zhang, T. Mu, Water sorption in ionic liquids: Kinetics, mechanisms and hydrophilicity, Phys. Chem. Chem. Phys. 14 (2012) 12252-12262. https://doi.org/10.1039/c2cp41798g.

[59] M.G. Freire, C.M.S.S. Neves, I.M. Marrucho, J.A.P. Coutinho, A.M. Fernandes, Hydrolysis of tetrafluoroborate and hexafluorophosphate counter ions in imidazolium-based ionic liquids, J. Phys. Chem. A. 114 (2010) 3744-3749. https://doi.org/10.1021/jp903292n.

[60] L. Cammarata, S.G. Kazarian, P.A. Salter, T. Welton, Molecular states of water in room temperature ionic liquids, Phys. Chem. Chem. Phys. 3 (2001) 51925200. https://doi.org/10.1039/b106900d.

[61] X. Wei, L. Yu, X. Jin, D. Wang, G.Z. Chen, Solar-thermochromism of pseudocrystalline nanodroplets of ionic liquid-NiII complexes immobilized inside translucent microporous PVDF films, Adv. Mater. 21 (2009) 776-780. https://doi.org/10.1002/adma.200801816. 
